\title{
Improved protocol for extracting genomic DNA from frozen formalin-fixed tissue resulting in high-quality whole mtDNA
}

\author{
H.W. Wang ${ }^{1,2 *}$, Y. Xu ${ }^{1 *}$, H.F. Zhang ${ }^{3}$, Y.J. Zeng ${ }^{1}$, L. Ren ${ }^{3}$, Y.L. Miao ${ }^{1}$, \\ H.Y. Luo ${ }^{1}$ and K.H. Wang ${ }^{1}$ \\ ${ }^{1}$ Yunnan Institute of Digestive Disease, \\ The First Affiliated Hospital of Kunming Medical University, Kunming, \\ Yunnan Province, China \\ ${ }^{2}$ Department of Reproduction and Genetics, \\ The First Affiliated Hospital of Kunming Medical University, Kunming, \\ Yunnan Province, China \\ ${ }^{3}$ The First People's Hospital of Yunnan Province, Kunming, Yunnan Province, \\ China \\ *These authors contributed equally to this study. \\ Corresponding authors: H.Y. Luo / K.H. Wang \\ E-mail: luohuayouyd@126.com / kunhuawang1@163.com
}

Genet. Mol. Res. 15 (3): gmr.15037972

Received October 30, 2015

Accepted January 15, 2015

Published August 26, 2016

DOI http://dx.doi.org/10.4238/gmr.15037972

Copyright (C) 2016 The Authors. This is an open-access article distributed under the terms of the Creative Commons Attribution ShareAlike (CC BY-SA) 4.0 License.

\begin{abstract}
Formalin fixation and paraffin embedding is widely used for convenient and long-term storage of tumor tissue and precious sources to perform genetic studies. However, DNA fragmentation is one of the major flaws of genomic DNA isolation from formalin fixation tissues, which limits its further usage. Here, we present an improved method for isolating high-quality genomic DNA from formalin fixation tissue. We obtained high-quality genomic DNA of more than $20 \mathrm{~kb}$
\end{abstract}


from samples frozen for more than 2 years. Furthermore, to verify DNA quality, the whole mitochondrial DNA (mtDNA) genomes from the normal and tumor tissue of the same patient were successfully amplified with two overlapping PCR fragments comprising more than $8379 \mathrm{bp}$ in length for each fragment. In addition, the whole genomes were sequenced with a 48-well based primer panel in order to avoid potential sequencing errors from artificial recombination, which was further confirmed with an mtDNA phylogenetic strategy. Our improved DNA extraction method from formalin fixation tissue and sequencing strategy for entire mtDNA genomes will generate unambiguous sequence analysis results for clinical samples.

Key words: Formalin-fixed tissue; DNA isolation; Entire mtDNA genome

\section{INTRODUCTION}

Formalin fixation is commonly used for preservation of pathological tissue and biological specimens. Formalin-fixed paraffin-embedded (FFPE) tissue contains a rich source of genetic material that can be used for medical research (Lipson et al., 2012; Chen et al., 2013) and biological disciplines (Santos et al., 2009) in downstream DNA-based experiments, such as copy number analysis (Gilbert et al., 2007; Jacobs et al., 2007), real-time quantitative polymerase chain reaction (RT-PCR) (Gjerdrum et al., 2004), single nucleotide polymorphism (SNP) bead arrays (Oosting et al., 2007), microarray comparative genomic hybridization (Vékony et al., 2007), and genome-wide sequencing (Aviel-Ronen et al., 2006; Schumer et al., 2013). However, formalin may cause the fragmentation of DNA (Douglas and Rogers, 1998), which reduces the quality and quantity of DNA (Poljak et al., 2000). Isolation of sufficient amounts of intact DNA from FFPE tissue is a challenge due to crosslinking between DNA and protein caused by formalin fixation, which decreases the quality of most DNA molecules by breaking them into $200 \mathrm{bp}$ or less fragments (Gilbert et al., 2007). A number of approaches have been published to obtain higher quality DNA from FFPE tissue; however, very highquality DNA has never been isolated (Farrugia et al., 2010; Okello et al., 2010). Therefore, in view of the invaluable resources contained in FFPE tissue on studying pathogenesis of cancer and a variety of other diseases, exploring an effective method to preserve and purify higher quality genomic DNA from FFPE tissue is imperative.

One of the critical steps for obtaining high-quality genomic DNA is to break up the crosslinks between DNA and protein during the extraction process (Srinivasan et al., 2002; Gilbert et al., 2007). Fortunately, the formation of these crosslinking is reversible in aqueous solution (Dubeau et al., 1986; Fang et al., 2002). Thus, the possibility of obtaining high-quality genomic DNA from FFPE tissue was presented by performing a pre-extraction procedure to remove paraffin from fixed tissues (Santos et al., 2009). Previous study has confirmed the superiority of genomic DNA after pretreatment of the FFPE tissues (Fang et al., 2002).

Mitochondria, the power source of the cell, are the major cellular component performing oxidative phosphorylation to supply energy to cells, and participate in complex apoptotic signaling pathways (Lee et al., 2004). Mitochondria also have their own genomic DNA and, since they lack the protection of histones, mitochondrial DNA (mtDNA) are more vulnerable

Genetics and Molecular Research 15 (3): gmr.15037972 
to oxidative damage. They also have poor DNA mismatch repair mechanisms (Croteau and Bohr, 1997), resulting in genome variations in mtDNA that are 10 to 200 times more frequent than those in nuclear genomic DNA (Larsen et al., 2005). Previous study indicates that mtDNA mutations are associated with various diseases (Schon et al., 2012), such as Leber hereditary optic neuropathy (Wallace et al., 1988), Leigh syndrome (de Vries et al., 1993), mitochondrial encephalomyopathy, lactic acidosis, and stroke-like episodes (Kirby et al., 2004). The somatic mutations detected in different tumor tissues may also relate to the process of cancer (Schon et al., 2012). As DNA fragmentation is the major shortcoming of FFPE tissues (Gilbert et al., 2007), the role of mtDNA mutations in cancer has been difficult to understand, partly due to the artificial recombination that occurs during processing of small PCR segments (Fendt et al., 2009). Considering the fact that formalin fixation is one of the most commonly used preservation methods for tumor tissues, it is important to be able to isolate intact genomic DNA and sequence the entire mtDNA genome in order to avoid artificial recombination.

In this study, we developed an improved protocol to extract higher quality genomic DNA from frozen formalin fixation colorectal cancer tissues that were frozen for more than 2 years. This protocol uses gradient ethanol to remove the formalin by reversing the crosslinks with genomic DNA in aqueous solution, and takes advantage of the good solubility of formaldehyde in water and ethanol (Fang et al., 2002). We were able to obtain 30 to $50 \mu \mathrm{g}$ high-quality total genomic DNA for each sample, the quality of which was verified by absorbance measurements and gel electrophoresis. Furthermore, two overlapping PCR fragments comprising over $8379 \mathrm{bp}$ in length were successfully amplified (Fendt et al., 2009) and high-quality genomic mtDNA was obtained according to our improved sequencing strategy.

\section{MATERIAL AND METHODS}

\section{Tissue specimens}

To perform the protocol for isolating genomic DNA from formalin fixation tissues, a total of 6 tissues from 2 colorectal cancer patients were collected randomly from our biological specimens' bank, including the primary colorectal cancerous tissue, two symmetrical adjacent cancerous tissues, and distant normal tissue, which were at least $5 \mathrm{~cm}$ away from the edge of the cancerous tissue. The tumor tissues were collected during surgery with consent and personal information was omitted during the process of data analysis and reporting. All procedures were supervised and approved by the Human Tissue Research Committee of the First People's Hospital of Yunnan Province. The study was performed according to the Declaration of Helsinki. The tumor tissues were verified with hematoxylin and eosin staining and the para-cancerous tissues were obtained from the symmetrical side of the cancer. The primary colorectal cancerous tissues and corresponding para-cancerous normal tissues were marked with $\mathrm{C}$ and $\mathrm{CP}$, respectively (Wang et al., 2011), fixed with an excess volume of $10 \%$ $(\mathrm{v} / \mathrm{v})$ formalin, and then stored at $-80^{\circ} \mathrm{C}$.

\section{DNA extraction}

Approximately $30 \mathrm{mg}$ frozen tissue was cut into small pieces and collected into a $1.5-\mathrm{mL}$ centrifuge tube. To reverse the crosslinking between DNA and protein, the formalin fixation tissues were initially soaked in $100 \%$ ethanol for $10 \mathrm{~min}$ then centrifuged at 12,000

Genetics and Molecular Research 15 (3): gmr.15037972 
rpm for $10 \mathrm{~min}$. This was followed by successive washes with gradient ethanol $(90,85,80,70$, and $50 \%$ ) and sterile water. After the final rehydration, the tissue was cut and ground with an electric mill (Tiangen Biotech Co., Ltd., Beijing, China). The suspension was digested with 10 $\mu \mathrm{g}$ Proteinase K and $100 \mu \mathrm{L}$ SDS buffer $(10 \%)$ for at least $16 \mathrm{~h}$ at $56^{\circ} \mathrm{C}$, and then mixed with $700 \mu \mathrm{L}$ Tris-saturated phenol for at least $12 \mathrm{~h}$. This was followed with the standard phenol/ chloroform method (Gross-Bellard et al., 1973) and the final genomic DNA was dissolved in $100 \mu \mathrm{L}$ TE buffer. The quality and integrity of genomic DNA was tested by gel electrophoresis on $1 \%$ agarose gels and compared to a $23-\mathrm{kbp}$ genomic DNA standard. The quantity and quality of the genomic DNA was measured with a NanoDrop ND-1000 spectrophotometer (NanoDrop Technologies, Wilmington, DE, USA) by calculating the ratio of absorbance readings at 260 and $280 \mathrm{~nm}\left(\mathrm{~A}_{260 / 280}\right)$.

\section{PCR amplification, sequencing, and quality control}

As the quality and quantity of genomic DNA extracted from FFPE tissues is poor (Gilbert et al. 2007), long fragments of PCR for mtDNA genomes were amplified and sequenced as two fragments comprising more than $8379 \mathrm{bp}$ in length for each fragment (Fendt et al., 2009). The entire mtDNA genomes of the two colorectal cancer patients were sequenced with 48 internal sequencing primers. The sequencing reactions were performed with the BigDye Terminator v3.1 cycle sequencing kit (Applied Biosystems, Foster City, CA, USA) on a 3700 DNA Analyzer (Applied Biosystems). Original sequences were edited and aligned with the DNASTAR software package version 7.0 (DNAStar Inc., Madison, WI, USA). Mutations in the mtDNA genome were scored according to the revised Cambridge Reference Sequence (rCRS) (Andrews et al., 1999). The phylogenetic status of the mtDNA genomes was determined according to the reconstructed East Asian mtDNA phylogeny (Kong et al., 2006).

To avoid sequencing errors prevalent in the medical field (Bandelt et al., 2007), strict quality control measures were followed in our procedure upon extracting genomic DNA and generating the mtDNA genome sequences. First, each sample was given a unique sample identification (ID) number and all samples were amplified and sequenced according to their sample IDs, which were verified at each step. Second, the entire mtDNA genome was amplified as two segments of more than 8379 bp each (Fendt et al., 2009), which can efficiently reduce the risk of artificial recombination caused by sample crossover and help to avoid the amplification of pseudo-mitochondrial genes from the nuclear genome. Third, a total of 48 internal primers were used for sequencing the entire mtDNA genome. These sequencing reactions were performed on the same 96-well plate, which can effectively reduce the potential for artificial recombination during the sequencing process. Lastly, variations were recorded and inspected by different experienced analysts and compared with the rCRS (Andrews et al., 1999). All suspicious variations were identified by a phylogenetic approach (Bandelt et al., 2007).

\section{RESULTS}

In order to isolate intact genomic DNA from frozen tissue for further genetic analysis, frozen tissue was pretreated to remove paraffin. This was done by first soaking the tissue in gradient ethanol and deionized water then cutting and grinding the tissue. The genomic DNA was further purified with a standard phenol/chloroform method. The quantity and quality of

Genetics and Molecular Research 15 (3): gmr.15037972 
the genomic DNA were evaluated with traditional agarose gel electrophoresis analysis and NanoDrop, and universal and long fragment PCR were performed and sequenced with our improved strategy. In addition, phylogenetic analysis for the whole mtDNA genomes of the two colorectal cancer patients was performed by comparing them to published mtDNA genomes (Wang et al., 2011).

To evaluate the integrity of the genomic DNA isolated from frozen formalin fixation samples, the genomic DNAs was analyzed by $1 \%$ agarose gel electrophoresis, as shown in Figure S1a. The intact genomic DNA, which was approximately $23 \mathrm{kbp}$ and extracted from the frozen formalin fixation tissues, was the same size as that isolated from the leukocytes of fresh blood (Fang et al., 2002). Our results indicate that the improved method can effectively isolate intact genomic DNA from frozen formalin fixation tissues (Figure S1a).

The quality and quantity of genomic DNA extracted from the frozen formalin fixation samples were evaluated. The total DNA was diluted 10-fold and the concentration of the diluted DNA was measured with a NanoDrop-1000. We obtained a high yield of genomic DNA from the 4 tissues, varying from 32.8 to $65.4 \mu \mathrm{g}$ (Table S1). The purity of the genomic DNA was assessed by the ratios of $\mathrm{A}_{260 / 280}$. As shown in Table S1, two genomic DNA samples had ratios of $\mathrm{A}_{260 / 280}$ between 1.8 and 2.0 and the other two samples had ratios of $\mathrm{A}_{260 / 280}$ slightly higher than 2.0. $\mathrm{A}_{260 / 280}$ values between 1.8 and 2.0 indicate an almost protein-free DNA samples while a ratio of $\mathrm{A}_{260 / 280}$ higher than 2.0 indicates the presence of contaminating RNA, which absorbs strongly at $260 \mathrm{~nm}$.

The quality of the genomic DNA isolated from the frozen formalin fixation tissues was also evaluated in terms of its successful PCR amplification and sequencing results (Fang et al., 2002; Santos et al., 2009). The whole mtDNA control region (around $1589 \mathrm{bp}$ ) was amplified with 1 pair of primers (Zhao et al., 2009), and the whole mtDNA genome (around 16,569 bp) was amplified with two covering fragments, which were 8379 and 8604 bp long (Fendt et al., 2009) (Figure S1b and $\underline{\text { S1c)}) . ~ W e ~ s u c c e s s f u l l y ~ o b t a i n e d ~ a l l ~ P C R ~ f r a g m e n t s ~ w i t h ~} 50 \mathrm{ng}$ genomic DNA, which was isolated from the frozen formalin fixation colorectal cancer tissue. The entire mtDNA genome was sequenced with 48 internal primers, which were arranged on the upper and lower parts of a 96-well plate for the two patients, respectively. This strategy avoids possible artificial recombination during the sequencing process. The primer sequences of the 48 internal primers were taken from the literature (Wang et al., 2008; Fendt et al., 2009). The mtDNA genomic sequences of the two patients were both allocated to haplogroup F1 for sharing a string of diagnostic variations (Figure 1). To further confirm the reliability of the two genomes, 12 whole mtDNA genomes were retrieved from more than 22,514 whole mtDNA genomes. As shown in Figure 1, the two whole mtDNA genomes have six and three private variations, which only appeared in the two new sequenced mtDNA genomes by comparing reported sequences of the same haplogroup. These were identified by comparing the genomes sharing much more basal variations with the sequence obtained in this study. In detail, patient $7 \mathrm{~B}$ has four control region variations (including variations $151,309+\mathrm{C}, 315+\mathrm{C}$, and $16193+\mathrm{C}$ ) and two coding region variations (containing variations 9272 and 15908). Patient 12B has two control region variations (including variations 143 and $315+\mathrm{C}$ ) and one coding region deletion (4314d). Furthermore, by screening these mutations among the 22,514 whole mtDNA genomes, we found that mutation 9272 was prevalent among African mtDNA haplogroup L3 and European mtDNA haplogroup J. Mutation 15908 was one of defining variations of mtDNA haplogroup M33a and M74b, and it also appeared in individuals of F4a. The adenine deletion was widely distributed among individuals of mtDNA haplogroup F1e2, and the

Genetics and Molecular Research 15 (3): gmr.15037972 
control region variations $143,151,309+\mathrm{C}, 315+\mathrm{C}$, and $16193+\mathrm{C}$ were hotspot mutations in mtDNA genomes, which imply that these mutations occurred randomly.

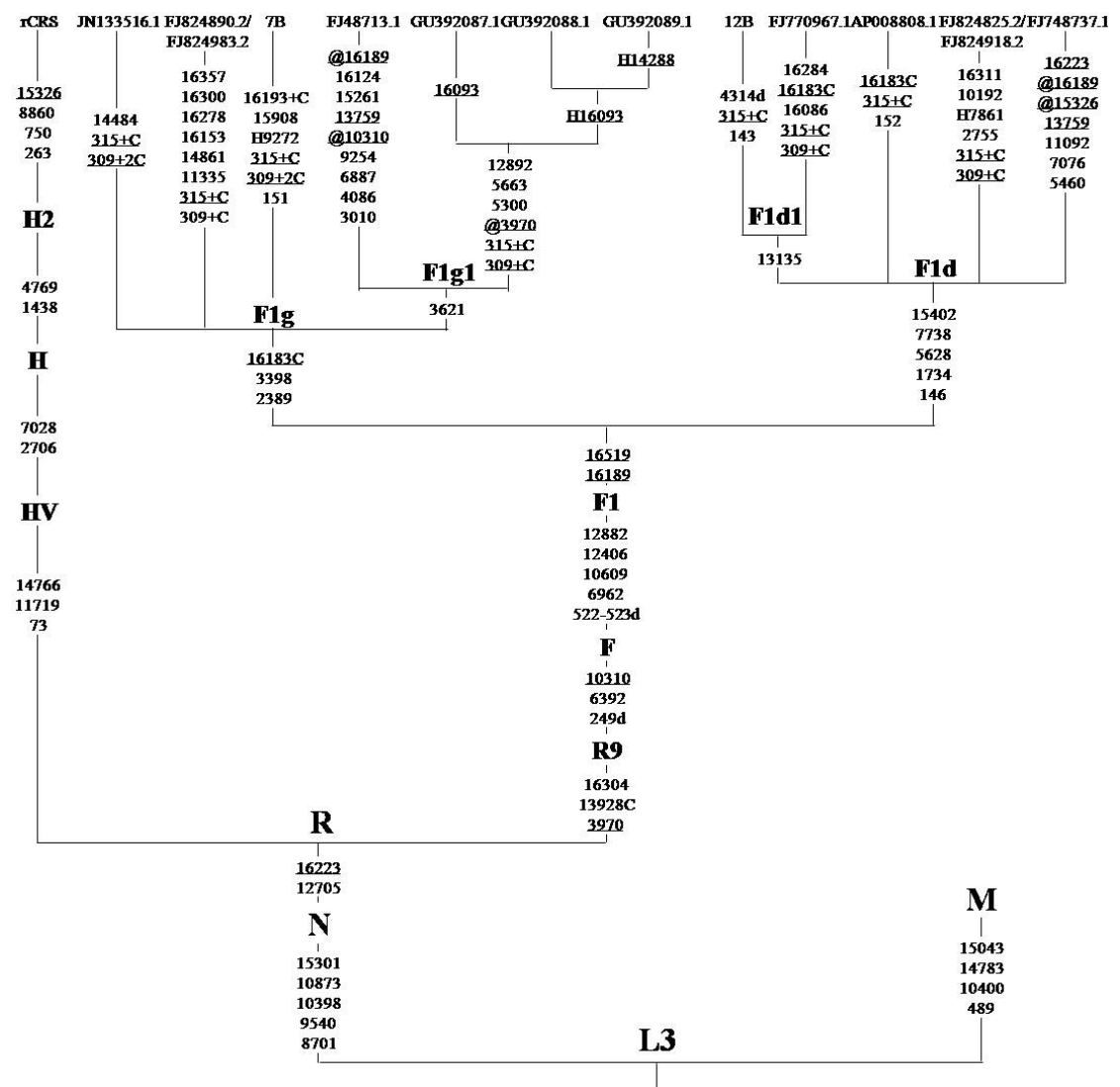

Figure 1. Phylogenetic tree of 14 complete mtDNA sequences including colorectal malignant tissues and healthy individuals from the literature. Haplogroup names are inserted along the branches, determining the location of the corresponding ancestral haplotypes. Variants (reconstructed most parsimoniously) on uninterrupted branches are listed arbitrarily in ascending order. Suffixes indicate transversions; "H" suggests heteroplasmic mutations, and "d" indicates a deletion. Recurrent variants are underlined. Length variation of C-tract around positions 310 and 16189 were assigned arbitrarily. The suffix "B" in the sample names indicate "cancerous tissue".

\section{DISCUSSION}

FFPE tissue is a broadly used method to preserve tumor tissue because it allows for stable storage conditions for the specimen, which is a valuable biological resource for studying genetic-based disease (Sengüven et al., 2014). However, the crosslinks between DNA and protein result in the degradation of genomic DNA, limiting its usage in genetic studies (Gilbert et al., 2007). In this study, the method for isolating genomic DNA from formalin fixation tissues was improved to achieve higher quality and quantity of DNA. This was primarily done by displacing the formalin from the tissues with a decreasing ethanol gradient and deionized water. We obtained genomic DNA that was $23 \mathrm{kbp}$ (Figure S1a), which was identical in size 
to DNA isolated from the leukocytes of fresh blood. In addition, the yield $\left(\mathrm{A}_{260 / 280}\right)$ of genomic DNA isolated from frozen formalin fixation tissue was better than that from blood leukocytes (Table S1). Our results indicate that removing the formalin from the formalin fixation tissues before isolating genomic DNA is a very important step (Fang et al., 2002).

The quality and quantity of the genomic DNA were evaluated by amplifying and sequencing fragments of 1589, 8379, and 8604 bp (Figure S1b and S1c). The latter two fragments covered the whole mtDNA genome. Our phylogenetic analysis supported the F1 haplogroup status of the two patients, F1g and F1d1. By comparing with 12 individuals sharing the identical mtDNA haplogroup status, which were retrieved from 22,514 whole mtDNA genomes, we found that most of the private variations were detected in the mtDNA control region. Therein, we found that heterogeneity was the main character of the variations, especially the C-tract around positions 310 and 16189, which varied in length. These two variations were also detected in patients with breast cancer, lung cancer, and type 2 diabetes (Alhomidi et al., 2013; Chen et al., 2016). Our results confirmed the reliability of the two whole mtDNA genomes of the patients with colorectal cancer, which implied that our sequencing strategy could reduce the risk of artificial recombination efficiently (Fendt et al., 2009; Bi et al., 2011). The complex purification process, which may enhance the opportunity for DNA contamination, was also verified based on the sequencing results of the non-recombinant whole mtDNA genomes. No other mutations belonging to different haplogroups were detected, thus further confirming the high quality of our protocol.

By comparing our DNA isolation strategy with those described in previous studies (Lin et al., 2009; Santos et al., 2009; Farrugia et al., 2010; Okello et al., 2010), our results indicate that the method of stocking frozen formalin fixation tissues for long periods of time is the major factor affecting the quality of genomic DNA. The pretreatment of the formalin fixation tissues by gradual dehydration can effectively reduce the crosslinking between histone proteins and DNA, even though formaldehyde cannot be completely removed (Fang et al., 2002). However, the proper ratios of $A_{260 / 280}$ and successful amplification of DNA fragments more than $8379 \mathrm{bp}$ in length support that triturating the pretreated tissues and digesting the suspensions with Proteinase K can effectively reduce crosslinking. The improved sequencing strategy and the analysis based on mtDNA phylogeny can generate high-quality sequences. In addition, this strategy can rapidly identify private mutations in patients with colorectal cancer, as described in previous studies (Bi et al., 2011). However, the pretreatment of tissue was time consuming, and the complex process may enhance the chances of DNA contamination.

In this study, we describe an effective protocol for isolating high-quality genomic DNA from frozen formalin fixation tissue. Amplifying whole mtDNA genomes with long PCR fragments, sequencing the whole genomes with our improved strategy, and analyzing the variation based on mtDNA phylogeny can generate higher quality sequences and identify private mutations rapidly. This will benefit future studies on investigating variation in mtDNA genomes in clinical fields.

\section{Conflicts of interest}

The authors declare no conflict of interest.

\section{ACKNOWLEDGMENTS}

Research supported by the Foundation for Science and Technology Planning

Genetics and Molecular Research 15 (3): gmr.15037972 
Project of Yunnan Provincial Bureau of Health (\#2012WS063); the Yunnan Institute of Digestive Disease Institute (\#2014NS121 and \#2014NS122); the China Postdoctoral Science Foundation (\#2014M562513XB); the National Science Foundation of China (\#81360069); the Academician Workstation of Yunnan Province; the Foundation for Innovative Group of Gastrointestinal Surgery of Yunnan Province (\#2012HC013); and the Foundation of Medical Leading Talent of Yunnan Province (\#L-201205).

\section{REFERENCES}

Alhomidi MA, Vedicherla B, Movva S, Rao PK, et al. (2013). Mitochondrial D310 instability in Asian Indian breast cancer patients. Tumour Biol. 34: 2427-2432. http://dx.doi.org/10.1007/s13277-013-0793-0

Andrews RM, Kubacka I, Chinnery PF, Lightowlers RN, et al. (1999). Reanalysis and revision of the Cambridge reference sequence for human mitochondrial DNA. Nat. Genet. 23: 147. http://dx.doi.org/10.1038/13779

Aviel-Ronen S, Qi Zhu C, Coe BP, Liu N, et al. (2006). Large fragment Bst DNA polymerase for whole genome amplification of DNA from formalin-fixed paraffin-embedded tissues. BMC Genomics 7: 312. http://dx.doi. org/10.1186/1471-2164-7-312

Bandelt HJ, Yao YG, Salas A, Kivisild T, et al. (2007). High penetrance of sequencing errors and interpretative shortcomings in mtDNA sequence analysis of LHON patients. Biochem. Biophys. Res. Commun. 352: 283-291. http://dx.doi.org/10.1016/j.bbrc.2006.10.131

Bi R, Li WL, Chen MQ, Zhu Z, et al. (2011). Rapid identification of mtDNA somatic mutations in gastric cancer tissues based on the mtDNA phylogeny. Mutat. Res. 709-710: 15-20. http://dx.doi.org/10.1016/j.mrfmmm.2011.02.016

Chen L, Li Y, Fu Y, Peng J, et al. (2013). Role of deregulated microRNAs in breast cancer progression using FFPE tissue. PLoS One 8: e54213.http://dx.doi.org/10.1371/journal.pone.0054213

Chen XZ, Fang Y, Shi YH, Cui JH, et al. (2016). Mitochondrial D310 instability in Chinese lung cancer patients. Mitochondrial DNA 27: 1177-1180. http://dx.doi.org/10.3109/19401736.2014.936426

Croteau DL and Bohr VA (1997). Repair of oxidative damage to nuclear and mitochondrial DNA in mammalian cells. $J$. Biol. Chem. 272: 25409-25412. http://dx.doi.org/10.1074/jbc.272.41.25409

de Vries DD, van Engelen BG, Gabreëls FJ, Ruitenbeek W, et al. (1993). A second missense mutation in the mitochondrial ATPase 6 gene in Leigh's syndrome. Ann. Neurol. 34: 410-412.http://dx.doi.org/10.1002/ana.410340319

Douglas MP and Rogers SO (1998). DNA damage caused by common cytological fixatives. Mutat. Res. 401: 77-88. http:// dx.doi.org/10.1016/S0027-5107(97)00314-X

Dubeau L, Chandler LA, Gralow JR, Nichols PW, et al. (1986). Southern blot analysis of DNA extracted from formalinfixed pathology specimens. Cancer Res. 46: 2964-2969.

Fang SG, Wan QH and Fujihara N (2002). Formalin removal from archival tissue by critical point drying. Biotechniques 33: 604, 606, 608-610.

Farrugia A, Keyser C and Ludes B (2010). Efficiency evaluation of a DNA extraction and purification protocol on archival formalin-fixed and paraffin-embedded tissue. Forensic Sci. Int. 194: e25-e28. http://dx.doi.org/10.1016/j. forsciint.2009.09.004

Fendt L, Zimmermann B, Daniaux M and Parson W (2009). Sequencing strategy for the whole mitochondrial genome resulting in high quality sequences. BMC Genomics 10: 139. http://dx.doi.org/10.1186/1471-2164-10-139

Gilbert MT, Haselkorn T, Bunce M, Sanchez JJ, et al. (2007). The isolation of nucleic acids from fixed, paraffin-embedded tissues-which methods are useful when? PLoS One 2: e537.http://dx.doi.org/10.1371/journal.pone.0000537

Gjerdrum LM, Sorensen BS, Kjeldsen E, Sorensen FB, et al. (2004). Real-time quantitative PCR of microdissected paraffin-embedded breast carcinoma: an alternative method for HER-2/neu analysis. J. Mol. Diagn. 6: 42-51. http:// dx.doi.org/10.1016/S1525-1578(10)60490-4

Gross-Bellard M, Oudet P and Chambon P (1973). Isolation of high-molecular-weight DNA from mammalian cells. Eur. J. Biochem. 36: 32-38. http://dx.doi.org/10.1111/j.1432-1033.1973.tb02881.x

Jacobs S, Thompson ER, Nannya Y, Yamamoto G, et al. (2007). Genome-wide, high-resolution detection of copy number, loss of heterozygosity, and genotypes from formalin-fixed, paraffin-embedded tumor tissue using microarrays. Cancer Res. 67: 2544-2551. http://dx.doi.org/10.1158/0008-5472.CAN-06-3597

Kirby DM, McFarland R, Ohtake A, Dunning C, et al. (2004). Mutations of the mitochondrial ND1 gene as a cause of MELAS. J. Med. Genet. 41: 784-789. http://dx.doi.org/10.1136/jmg.2004.020537

Kong QP, Bandelt HJ, Sun C, Yao YG, et al. (2006). Updating the East Asian mtDNA phylogeny: a prerequisite for the identification of pathogenic mutations. Hum. Mol. Genet. 15: 2076-2086. http://dx.doi.org/10.1093/hmg/dd1130

Genetics and Molecular Research 15 (3): gmr.15037972 
Larsen NB, Rasmussen M and Rasmussen LJ (2005). Nuclear and mitochondrial DNA repair: similar pathways? Mitochondrion 5: 89-108.http://dx.doi.org/10.1016/j.mito.2005.02.002

Lee YJ, Jeong SY, Karbowski M, Smith CL, et al. (2004). Roles of the mammalian mitochondrial fission and fusion mediators Fis1, Drp1, and Opa1 in apoptosis. Mol. Biol. Cell 15: 5001-5011.http://dx.doi.org/10.1091/mbc.E04$\underline{04-0294}$

Lin J, Kennedy SH, Svarovsky T, Rogers J, et al. (2009). High-quality genomic DNA extraction from formalin-fixed and paraffin-embedded samples deparaffinized using mineral oil. Anal. Biochem. 395: 265-267. http://dx.doi. org/10.1016/j.ab.2009.08.016

Lipson D, Capelletti M, Yelensky R, Otto G, et al. (2012). Identification of new ALK and RET gene fusions from colorectal and lung cancer biopsies. Nat. Med. 18: 382-384.http://dx.doi.org/10.1038/nm.2673

Okello JB, Zurek J, Devault AM, Kuch M, et al. (2010). Comparison of methods in the recovery of nucleic acids from archival formalin-fixed paraffin-embedded autopsy tissues. Anal. Biochem. 400: 110-117. http://dx.doi.org/10.1016/j. ab.2010.01.014

Oosting J, Lips EH, van Eijk R, Eilers PH, et al. (2007). High-resolution copy number analysis of paraffin-embedded archival tissue using SNP BeadArrays. Genome Res. 17: 368-376. http://dx.doi.org/10.1101/gr.5686107

Poljak M, Seme K and Gale N (2000). Rapid extraction of DNA from archival clinical specimens: our experiences. Pflugers Arch. 439 (Suppl): R42-R44.http://dx.doi.org/10.1007/s004240000085

Santos S, Sá D, Bastos E, Guedes-Pinto H, et al. (2009). An efficient protocol for genomic DNA extraction from formalinfixed paraffin-embedded tissues. Res. Vet. Sci. 86: 421-426. http://dx.doi.org/10.1016/j.rvsc.2008.08.007

Schon EA, DiMauro S and Hirano M (2012). Human mitochondrial DNA: roles of inherited and somatic mutations. Nat. Rev. Genet. 13: 878-890. http://dx.doi.org/10.1038/nrg3275

Schumer M, Cui R, Boussau B, Walter R, et al. (2013). An evaluation of the hybrid speciation hypothesis for Xiphophorus clemenciae based on whole genome sequences. Evolution 67: 1155-1168. http://dx.doi.org/10.1111/evo.12009

Sengüven B, Baris E, Oygur T and Berktas M (2014). Comparison of methods for the extraction of DNA from formalinfixed, paraffin-embedded archival tissues. Int. J. Med. Sci. 11: 494-499. http://dx.doi.org/10.7150/ijms.8842

Srinivasan M, Sedmak D and Jewell S (2002). Effect of fixatives and tissue processing on the content and integrity of nucleic acids. Am. J. Pathol. 161: 1961-1971. http://dx.doi.org/10.1016/S0002-9440(10)64472-0

Vékony H, Ylstra B, Wilting SM, Meijer GA, et al. (2007). DNA copy number gains at loci of growth factors and their receptors in salivary gland adenoid cystic carcinoma. Clin. Cancer Res. 13: 3133-3139. http://dx.doi. org/10.1158/1078-0432.CCR-06-2555

Wallace DC, Singh G, Lott MT, Hodge JA, et al. (1988). Mitochondrial DNA mutation associated with Leber's hereditary optic neuropathy. Science 242: 1427-1430. http://dx.doi.org/10.1126/science.3201231

Wang CY, Li H, Hao XD, Liu J, et al. (2011). Uncovering the profile of somatic mtDNA mutations in Chinese colorectal cancer patients. PLoS One 6: e21613.http://dx.doi.org/10.1371/journal.pone.0021613

Wang HW, Jia X, Ji Y, Kong QP, et al. (2008). Strikingly different penetrance of LHON in two Chinese families with primary mutation G11778A is independent of mtDNA haplogroup background and secondary mutation G13708A. Mutat. Res. 643: 48-53.http://dx.doi.org/10.1016/j.mrfmmm.2008.06.004

Zhao M, Kong QP, Wang HW, Peng MS, et al. (2009). Mitochondrial genome evidence reveals successful Late Paleolithic settlement on the Tibetan Plateau. Proc. Natl. Acad. Sci. USA 106: 21230-21235. http://dx.doi.org/10.1073/ pnas.0907844106

\section{Supplementary material}

Figure S1.a. Represents the electrophoretogram of total genomic DNA; b. shows the PCR fragment of the mtDNA control region covering $1569 \mathrm{bp}$; and c. denotes the PCR fragments of $8379 \mathrm{bp}$ (A) and $8604 \mathrm{bp}(\mathrm{B})$, which covered the whole mtDNA genome. In (a) and (c), the molecular weight marker was $23 \mathrm{kbp}$ and in (b), the molecular weight marker was the DL2000 DNA marker.

Table S1. $A_{260 / A 280}$ ratios of genomic DNA isolated from two formalin-fixed tissues. 